\title{
Cratonization and thermal evolution of the mantle
}

\author{
Henry N. Pollack \\ Department of Geological Sciences, University of Michigan, Ann Arbor, MI 48109-1063 (U.S.A.)
}

Received May 8, 1986; revised version received July 11, 1986

\begin{abstract}
The stabilization of continental lithosphere to form cratons is accomplished by volatile loss from the upper mantle during magmatic events associated with the formation of continental crust. Volatile depletion elevates the solidus and increases the stiffness of the mantle residuum, thereby imparting a resistance to subsequent melting and deformation. Freeboard is maintained in part by the buoyancy associated with an increased $\mathrm{Mg} /(\mathrm{Mg}+\mathrm{Fe})$ ratio in the mantle residuum following extraction of crustal material. Augmented subcratonic seismic velocities derive from the same shift in this ratio. The higher effective viscosity of the stabilized subcratonic upper mantle inhibits its entrainment in mantle convection, and locally thickens the conductive boundary layer. Heat approaching from greater depths is diverted away from the stiff craton to other areas that continue to transfer heat by convection, thus yielding a low surface heat flow within cratons.

Cratonization by devolatilization and petrologic depletion was most effective in the Archean and has diminished in effectiveness over geologic time as the mantle temperature has fallen because of the declining store of internal heat. From the Archean to the present that ascending mantle material which has undergone partial melting has encountered the solidus at progressively shallower depth, has remained supersolidus over a smaller depth range, has temperatures which have exceeded the solidus by lesser amounts, has undergone diminishing degrees of partial melting, and has experienced less thorough devolatilization. At a given time the rate of production of continental crust is likely to be proportional to the depth extent and fraction of partial melting. Integration of the partial melt zone over time yields a growth curve that is similar to some continental crustal growth curves inferred from isotopic evolution.
\end{abstract}

\section{Introduction}

The purpose of this paper is to set forth a model of the process by which continental lithosphere is stabilized to form cratons, and to examine how this process may have evolved through geologic time. I use the term craton in its traditional geologic sense as continental crust that has attained stability and has been unaffected by orogenic activity for a prolonged period of time. At the same time, however, I make the case that the development of cratonic stability is intimately associated with important changes in the subcratonic mantle.

The stability of cratons is characteristically displayed in at least three ways: (1) resistance to internal deformation, (2) a paucity of magmatism, and (3) maintenance of freeboard. Of course one can cite exceptions to each of these, including extensional dyke swarms, anorogenic magmatism, and marine supracrustal sedimentary sequences within cratons. However, large-scale and pervasive deformation and magmatism are clearly confined to the pre-stabilization history of the cratons, and marine incursions onto the stabilized cratons are generally short-term transients. Cratons are truly islands of stability within a generally mobile and less stable lithosphere.

How do cratons acquire and maintain the properties that give them long-term stability? As with oceanic lithosphere, thermal thickening must be one factor in the stabilization process. Early estimates of lithospheric thickness [1], based on surface heat flow and extrapolated geotherms, suggested that the cratonic lithosphere extends to depths of some $300 \mathrm{~km}$. Jordan [2-4] has also vigorously advocated thick root zones beneath the continental cratons. The seismological evidence advanced by him to substantiate the deep roots was debated for some time, but the issue now seems resolved by recent complementary observations [5-7] that confirm differences in seismic velocities, extending to $400 \mathrm{~km}$ depth, between the upper mantle beneath cratons and that beneath 
non-cratonic parts of continents as well as oceans. Investigations of upper mantle electrical conductivity also indicate highly resistive roots extending to similar depths beneath cratons [8].

Jordan has argued that thermal scenarios alone are inadequate to explain the stabilization of cratonic lithosphere. He invokes a complementary stabilizing mechanism involving a distinctive buoyant composition for the cratonic root that would compensate for the increased density and subsidence associated with the cooling of the lithosphere following a major tectonothermal event. His assessment that wholly thermal stabilization models are inadequate is persuasive, and his advancement of a compositional compensation mechanism has provided new insights into stabilization by focussing on the petrological depletion processes associated with tectonothermal events.

However, even Jordan's fuller description of the stabilization process remains incomplete. A significant element that must accompany the thermal and petrological aspects of stabilization is the depletion of volatiles from the sub-cratonic upper mantle. It is my opinion that devolatilization, particularly associated with periods of significant growth of continental crust in the early Precambrian, is a critical and essential aspect of the stabilization process.

\section{Volatiles, melting, and deformation}

Evidence that shows the significance of volatile depletion for stabilization derives from experiments on incipient melting, and on differential stress required to produce steady flow in rocks, each performed in the presence and absence of volatiles. Fig. 1 summarizes experimentally observed effects of the volatile environment on the solidus of peridotite $[9,10]$. The observational data on which Fig. 1 is based derives principally from experiments below $5 \mathrm{GPa}$, although investigations [11] at pressures to $14 \mathrm{GPa}$ are beginning to constrain melting relations deeper within the upper mantle. The effects are not exactly the same for each volatile species, or for different volatile ratios in a mixed-volatile environment. Nevertheless, the general effect of devolatilization is clear: incipient melting of mantle peridotite in a volatile-free environment requires temperatures $300-600^{\circ} \mathrm{C}$ higher, or pressures nearly $60 \mathrm{kbar}$

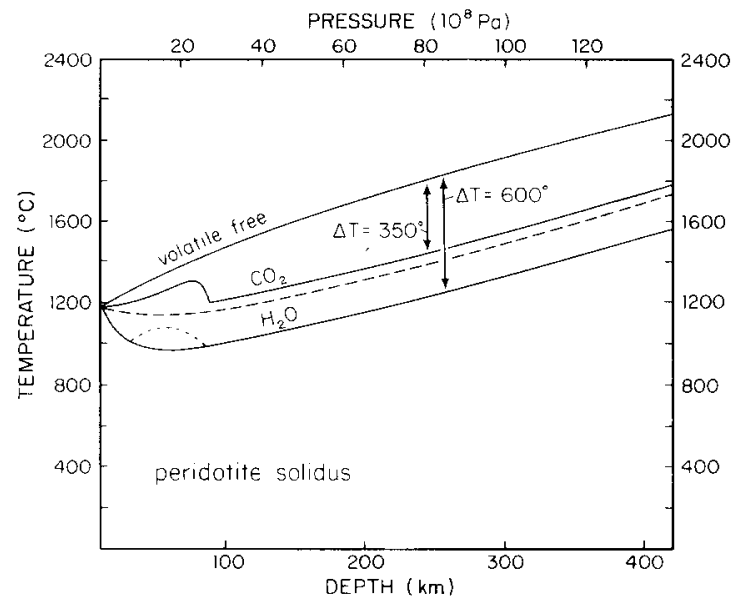

Fig. 1. Peridotite solidus in different volatile environments, after Wyllie $[9,10]$. Dashed line between $\mathrm{CO}_{2}$ and $\mathrm{H}_{2} \mathrm{O}$ is generalized solidus for a mixed volatile environment comprising equal amounts of $\mathrm{CO}_{2}$ and $\mathrm{H}_{2} \mathrm{O}$. Also shown are characteristic temperature differences between volatile-free and volatile-rich soliduses.

less, than in a volatile-rich environment. Devolatilization therefore elevates the solidus within the upper mantle, in effect making the mantle more refractory and less vulnerable to subsequent melting. Jordan [3] recognized that a garnet lherzolite which had undergone partial fusion and removal of components with low melting temperatures ("basalt depletion") would lead to a more refractory residuum. However, the effect devolatilization has on elevating the solidus overshadows the similar but lesser consequences of selective fusion.

Devolatilization has substantial effects on mechanical properties as well. Fig. 2 shows the generalized results of flow stress experiments on dunite referenced to a uniform strain rate, as a function of temperature and volatile environment [12-14]. The effect of devolatilization can be seen clearly: the given strain rate can be achieved at the same differential stress only if the temperature is elevated by some $450^{\circ} \mathrm{C}$. Or, the strain rate can be achieved at $1000^{\circ} \mathrm{C}$ only if the differential stress is increased by almost two orders of magnitude, and at $2000^{\circ} \mathrm{C}$ by one order of magnitude. Other experiments on polycrystalline olivine [15-17] show some variation in the magnitude of strain rate produced by a given differential stress, but consistently confirm the 1-2 orders of magnitude 


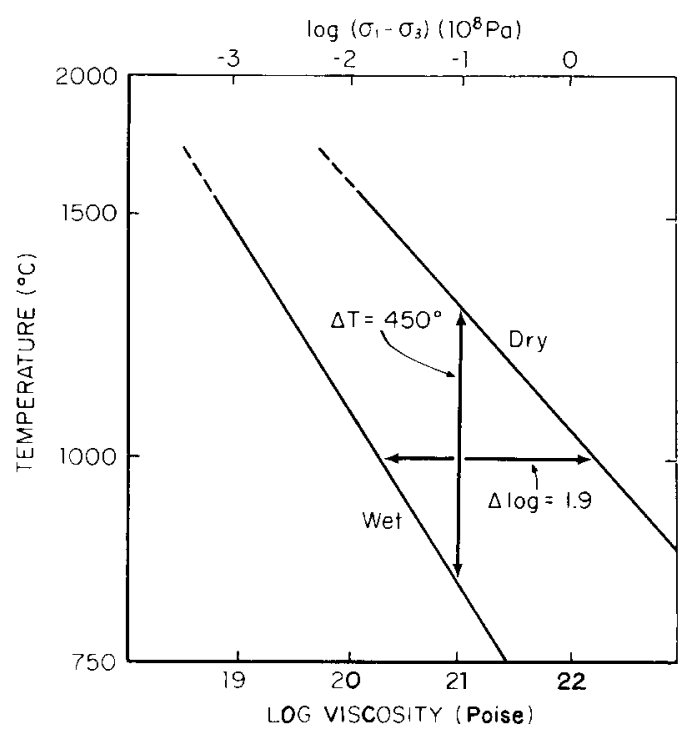

Fig. 2. Steady-state flow stress in dunite at strain rate of $10^{-14}$ $\mathrm{s}^{-1}$ as a function of temperature in different volatile environments, after Carter [14]. Also shown are temperature and stress differences characteristic of the deformation in volatile-rich and volatile-free environments.

stiffening accompanying volatile loss. Because much higher differential stress is required to force creep at a given rate in a devolatilized zone of upper mantle, such a volume will be more resistant to the rigors of tectonic buffeting than a volatile-rich counterpart. Similar arguments led Karato [18] to conclude that partial melting accompanied by volatile loss would not lead to a decoupling of the overlying lithosphere from the partial melt zone.

The resultant stiffening of the devolatilized region will also have a significant effect on the mode and pattern of heat transfer in the upper mantle. The increased viscosity will inhibit convection within the affected zone, isolating it from the general ongoing convection below and leaving conduction as the mode of heat transfer within. And, as the lithosphere is commonly defined in thermal terms as a boundary layer in which conduction is the principal mode of heat transfer, one sees that inhibiting convection in a region of the upper mantle by devolatilization is essentially equivalent to an extension of the zone of conduction to much greater depths, and therefore equivalent to a substantial thickening of the litho- sphere. The thickened boundary layer will be accompanied by a reduction in heat flow through it, and will lead to an adjustment in the convection beneath and peripheral to it so as to maintain the integrated regional heat flux [19].

That devolatilization has similar effects on both incipient melting and viscosity, i.e. requiring temperatures several hundred degrees higher in a volatile-free environment to achieve conditions and/or properties found in cooler volatile-rich settings, is a natural consequence of the fact that both melting and solid state creep are thermally activated processes, with activation energies for both substantially higher in a volatile-free environment. The amount of volatiles necessary to reduce the activation energy is small; the estimated 0.1 wt. $\% \mathrm{H}_{2} \mathrm{O}$ in the undepleted upper mantle $[20]$ is certainly sufficient.

\section{Process of cratonization}

A comparison of the thermal and dynamic conditions in the upper mantle beneath cratons both before and after devolatilization shows a clear contrast between a mobile regime and a stable one. A volatile-rich upper mantle is characterized by both a low solidus and low viscosity. The low viscosity promotes a freely convecting mantle, with plumes and diapirs rising adiabatically. Most of this heat and mass transfer remains subsolidus, but in places the ascending material crosses the depressed solidus and initiates partial melting. The $1600^{\circ}$ adiabat shown in Fig. 3a is characteristic of early Archean partial melts from the mantle, erupted at temperatures some $300-400^{\circ}$ warmer than present-day melt products from the mantle. This high-temperature adiabat encounters the solidus at depths greater than $400 \mathrm{~km}$ and reaches a maximum partial melt in excess of $50 \%$, thus creating the conditions favorable to komatiite formation. The volatiles partition preferentially into the partial melt and migrate upward, leaving a devolatilized refractory mantle residuum. The volatiles may be immobilized when they reach the cooler levels of the crust, or facilitate the differentiation of granitic magmas. Alternatively, the volatiles may stream through the crust to be liberated to the hydrosphere and atmosphere. The large-ion lithophile and incompatible elements in general, including the heat-producing radioiso- 


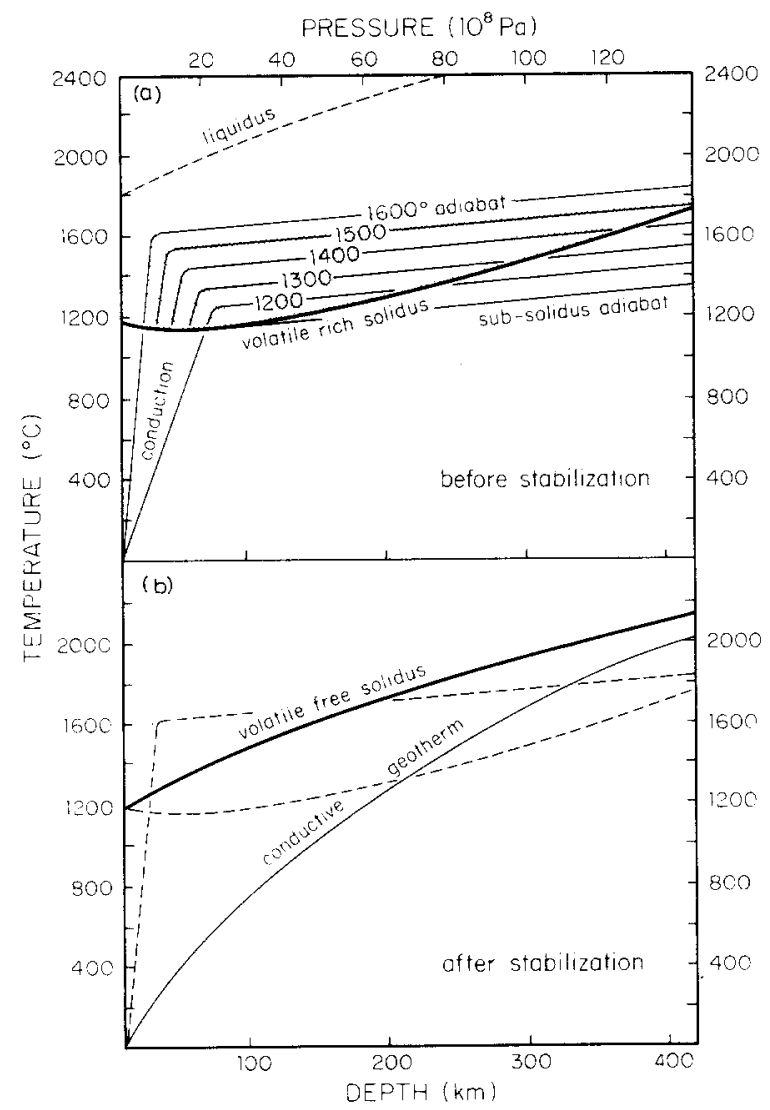

Fig. 3. (a) Volatile-rich upper mantle with applicable solidus prior to stabilization. Adiabats characterize local partial melting regimes in generally subsolidus convecting mantle, as mean mantle temperature diminishes (non-linearly) with time; shaded region is zone of partial melting. Also shown are steep conductive geotherms through a thin but slowly thickening thermal boundary layer. (b) Volatile-free cratonic upper mantle with applicable solidus after stabilization. Former volatile-rich solidus and $1600^{\circ} \mathrm{C}$ adiabat shown as dashed lines. Low heat-flow subsolidus superadiabatic conductive geotherm extends throughout stabilized lithosphere.

topes of $\mathrm{U}$, Th and $\mathrm{K}$, will also be mobilized upward and concentrated principally in the crust. The heat production in the depleted mantle residuum will be less by at least a factor of three, and perhaps an order of magnitude, than before depletion [21]. The efficient convective heat transfer associated with the mobile regime delivers substantial heat to high levels in the upper mantle for passage to the surface through a thin conductive boundary layer which is in a relatively weak and vulnerable condition mechanically due to thinness and local penetrative magmatism.
The contrasting condition of the upper mantle after devolatilization is shown in Fig. $3 b$. The elevated volatile-free solidus makes subsequent melting events more difficult, and the augmented shear strength enhances mechanical stability. Thus two of the significant characteristics of cratonic stability are achieved. The greater viscosity inhibits convection thus leading to heat transfer only by conduction throughout the stiffened devolatilized zone. The entirely conductive geotherm shown in Fig. 3b is consistent with the characteristic heat flow of cratons and the observed depleted mantle heat production. The curvature of the geotherm in the mantle arises not from heat sources, but from the temperature dependence of thermal conductivity. The geotherm is superadiabatic throughout the upper mantle, and actually reaches temperatures in excess of the pre-stabilization conditions in the deeper reaches of the devolatilized zone. However, in terms of the ratio of ambient to melting temperatures, the post-stabilization thermal regime is "cooler" throughout the devolatilized zone, inasmuch as the geotherm never reaches the solidus, whereas in the pre-stabilization regime extensive partial melting occurs. Less than half the heat formerly transported through this parcel of mantle before stabilization moves through it later by conduction. Heat approaching the region from greater depths is diverted away from the stiff craton to other areas that remain able to transfer heat efficiently by convection [19].

While it is the depletion of volatiles that makes the stabilized mantle refractory and stiff, it is, as Jordan has recognized, petrologic (major element) depletion that provides the buoyancy to compensate for the density differences that exist between mobile and stabilized upper mantle because of their different thermal structure. This buoyancy will contribute significantly to the maintenance of freeboard, although there are global aspects to freeboard [22] that preclude a local process such as cratonization being the sole determinant of freeboard. Jordan [23] presents detailed arguments to show that the requisite buoyancy may arise from the extraction of basaltic constituents, e.g. $\mathrm{Al}_{2} \mathrm{O}_{3}, \mathrm{FeO}, \mathrm{CaO}$, from peridotite. However, virtually any magmatic process that leaves the residual mantle more magnesian relative to iron will enhance the buoyancy of the residuum. Partial 
melting of any reasonable model of upper mantle petrology, even to fairly large melt fractions, will leave a residuum with an enhanced $\mathrm{Mg} /(\mathrm{Mg}+\mathrm{Fe})$ ratio. Such a depletion process will also raise the seismic velocities of the residuum [23-25]. The largest difference in shear velocity between cratonic and 'tectonic' upper mantle in North America is less than $0.5 \mathrm{~km} \mathrm{~s}^{-1}$ [5], about half of which is due to the temperature dependence of the velocity and is not of compositional origin. Probably no more than $0.25 \mathrm{~km} \mathrm{~s}^{-1}$ need be derived from a higher $\mathrm{Mg} /(\mathrm{Mg}+\mathrm{Fe})$ ratio in the upper mantle of the North American craton as compared to the upper mantle in the tectonically active Cordillera.

\section{Stabilization through time}

How long does it take for cratonic stabilization to develop? The geological record suggests that the process in the early Archean was quite rapid, probably because the relatively high degree of partial melting promoted efficient and extensive devolatilization. In the Kaapvaal craton of southern Africa one finds volcanic and plutonic rocks of the pre-stabilization regime with ages of 3.5 $\mathrm{Ga}$; these rocks form a stable platform for sedimentary deposits of $3.0 \mathrm{Ga}$ age. The undeformed sediments show clear and well-preserved depositional features today, indicating that the surface of the craton had stabilized by $3.0 \mathrm{Ga}$ and has been stable virtually ever since. Also, as clearly as 3.28 $\mathrm{Ga}$ the Kaapvaal craton existed as a rigid coherent unit imparting a structural grain to the tectonic fabrics developing in the adjacent Limpopo mobile belt [26].

The recent demonstration [27] of $3.2-3.3 \mathrm{Ga}$ ages for diamond xenocrysts in two Cretaceous kimberlites in South Africa provides evidence for early deep-seated stability as well. Geothermometry and barometry [28] show that the $P-T$ environment of formation of the diamonds was at nearly $200 \mathrm{~km}$ depth along the post-stabilization geotherm, thus indicating that at the time of diamond formation stabilization to such depth had already been completed. Moreover, the observation of pyroxene solid solution in diamond-enveloped garnets from a third South African kimberlite [29] suggests some diamond formation occurred at depths substantially greater than $200 \mathrm{~km}$. Stabili- zation throughout the Archean cratonic lithosphere was therefore not a slow and gradual process, extending over aeons, but rather a relatively rapid process, being essentially completed in a period on the order of a few hundred million years.

Studies [30,31] of initial strontium and neodymium isotopic ratios of carbonatites and related alkalic rocks from the mantle beneath the Superior Province of Canada also provide evidence for the ancient stabilization of cratonic upper mantle. These alkalic rocks, intruded at different times between $2.7 \mathrm{Ga}$ and $110 \mathrm{Ma}$, suggest a major crustal extraction event $2.9 \mathrm{Ga}$ ago that produced a depleted residual upper mantle that has remained coupled with the crust and served as a source for the alkalic magmas ever since.

The process of cratonization, however, is likely to slow through geologic time, because devolatilization of the upper mantle becomes progressively less efficient. The efficiency of devolatilization is linked to the fractional extent and depth range of partial melting, and both quantities are likely to have been much greater in the Archean than in the present-day. Fig. 4 shows the decline of the mean mantle temperature over time following the decay of radiogenic heat sources and the concomitant slowing of mantle convection [32]. The mean mantle temperature characterizes the large-scale sub-

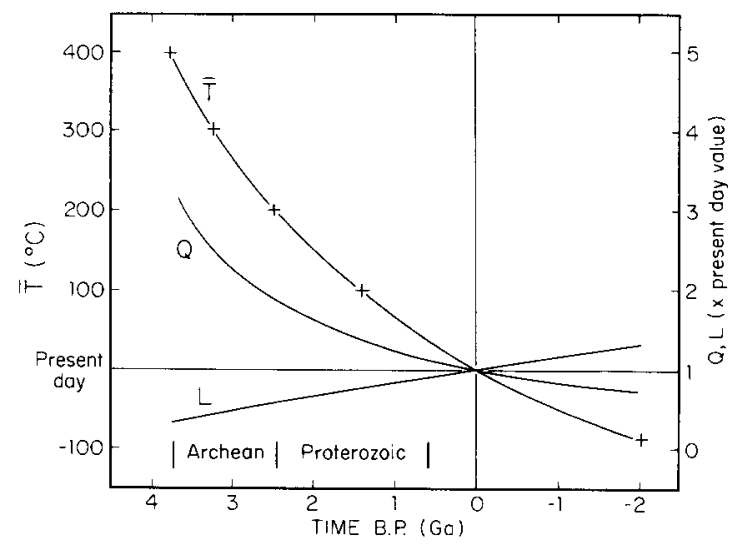

Fig. 4. Mean mantle temperature $(T)$, heat production $(Q)$, and thermal boundary layer thickness $(L)$, referred to presentday values, through time, after Jackson and Pollack [32]. Points along temperature curve at past times are at $100^{\circ} \mathrm{C}$ intervals and provide a time scale for the succession of adiabats in Fig. 3a. Point at $2 \mathrm{Ga}$ in future is when mantle will be entirely subsolidus. 
solidus heat and mass transfer, but local deviations from the mean that lead to partial melting may reasonably be expected to follow a similar history. Thus Fig. 4 enables the establishment of an approximate time scale for the succession of adiabats shown in Fig. 3a. The succession is nonlinear in time; the three higher-temperature adiabats encompass Archean conditions in the 3.85 to $2.60 \mathrm{Ga}$ interval, whereas the two cooler adiabats are more representative of mid-Proterozoic to present-day conditions. This temporal succession of adiabats suggests that rising plumes and diapirs which encounter the volatile-rich solidus will do so at progressively shallower depths, their temperatures will exceed the solidus by lesser amounts, they will remain supersolidus over smaller depth ranges, the degree of partial melting will diminish, and the accompanying devolatilization will be less complete. Moreover, the composition of the partial melt may evolve from komatiite through picrite to basalt [11]. The rapid and pervasive liberation of volatiles characteristic of the early Archean partial melting regime will gradually give way to magmatic events which alter lesser volumes of the mantle in less dramatic ways. Ultimately the mantle temperature will fall enough so that all diapirs will remain below the solidus throughout their ascent and therefore initiate no volatile release. At that point in time, approximately $2 \mathrm{Ga}$ in the future, cratonization by devolatilization will cease to be a significant geologic process.

Another aspect of the global cooling, the thickening of the conductive thermal boundary layer as the rate of heat loss from the earth diminishes, also plays a role, albeit a lesser one, in lithospheric stabilization. This effect can be seen in Fig. 3a as the gradually increasing depth at which the geotherm reflects the transition from a convective (adiabatic) to conductive (strongly superadiabatic) regime, and in Fig. 4 where the thickness of the thermal boundary layer is shown directly as a function of time. The pace of this lithospheric thickening process is considerably slower than that associated with devolatilization. During the Archean, cooling alone would have thickened the lithosphere by less than $25 \mathrm{~km}$, whereas devolatilization, where it occurred, extended the lithosphere by several hundred kilometers. Even in the $2 \mathrm{Ga}$ time interval from the present day to that future time when the mantle will remain entirely subsolidus, the secular cooling will thicken the lithosphere by only another $25 \mathrm{~km}$ or so.

The extent of partial melting, which exerts such a strong control on devolatilization and cratonization, is likely also to be correlated with the production of continental crust in general, because the production of continental crust is almost certainly related genetically to partial melting. The integral over depth of the supersolidus segment of an adiabat should be proportional to the rate of crustal production at that time. The integration in time over successive adiabats would then have the form of a cumulative crustal growth curve. This latter integration, over the succession of adiabats of Fig. 3a occurring at the times shown in Fig. 4, and normalized to unity at the present day, is shown in Fig. 5 along with several other proposed continental growth curves [33]. The growth curve derived here from the extent of partial melting through time is very similar to some growth curves

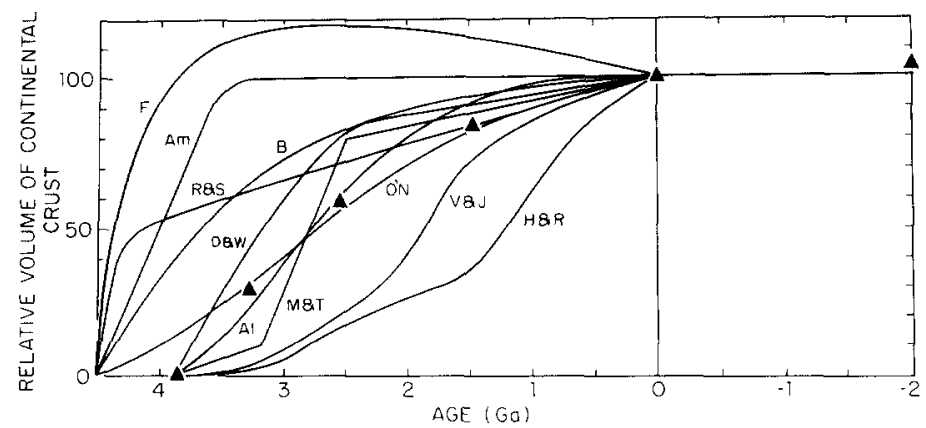

Fig. 5. Crustal growth curves, after Reymer and Schubert [33]. Identifying codes $R \& S, O^{\prime} N, A l, M \& T, F, A m, B, D \& W, V \& J$, $H \& R$ refer respectively to references $33,34,35,36,37,38,39,40,41,42$. Triangles represent integral over time of the partial melt zone of the succession of adiabats in Fig. $3 \mathrm{a}$, normalized to unity at the present day; rate of production of continental crust is assumed to be proportional to extent of partial melting. 
based on isotopic evolution arguments [34-36]. Some of the other curves shown are derived from considerations such as sediment recycling, rareearth chemistry and free-board requirements, each less directly linked to the primary partial melting process in the mantle than are the isotopic systems. Thus it is not surprising that the thermal and partial melting scenario presented here bears a close resemblance to isotopically inferred histories.

\section{Retrospective}

The image of the Archean envisioned by many earth scientists is characterized by high heat production, vigorous convection, and highly mobile tectonism and magmatism - in sum an image of an energetic and unstable early earth. It is, therefore, perhaps a surprising conclusion that the Archean was the best time for making cratons. That true cratonic nuclei were generated most abundantly and effectively in the Archean stems from the fact that the dynamic early earth was also a setting which in places promoted an efficient and thorough mobilization of volatiles from certain segments of pre-cratonic upper mantle.

Prior to $4 \mathrm{Ga}$ petrologic differentiation and volatile mobilization must have been even more vigorous than in the early Archean, with some volatiles liberated to the hydrosphere and atmosphere. However, the volatiles immobilized in primitive pre-Archean crust were likely returned to the mantle with that crust, to participate in later magmatism and crustal production. The present day is also not a wholly satisfactory guide to the geodynamics of the Archean. The Archean lithospheric recycling rate (production and consumption) was substantially greater than at present but the fraction of recycling at continental margins was substantially less because of the smaller area of the Archean proto-continents. Most lithospheric recycling occurred in a wholly oceanic setting. Continental marginal accretion was probably a secondary process in the Archean, overshadowed by the heat and mass transfer of ubiquitous vertical plumes and diapirs under- and overplating a young thin lithosphere.

The evolution of the earth from the Archean to the present-day has been dominated by the declining store of internal energy. In detail, however, the evolution has been richly multi-faceted. It has expressed itself as an evolution of mantle temperature, viscosity and solidus, of lithospheric thickness and plate dimensions, of the depth extent and fraction of partial melting and the petrology of the melt, and of the major and trace element and volatile distribution within the mantle and crust. In that evolutionary scenario the Archean was a special time for the generation of continental crust and the making of durable cratons.

\section{Acknowledgements}

I thank Alan Beck for the hospitality and facilities of the Department of Geophysics, University of Western Ontario, where this paper was written. This research was supported in part by NSF Grant EAR-8319394.

\section{References}

1 D.S. Chapman and H.N. Pollack, Regional geotherms and lithospheric thickness, Geology 5, 265-268, 1977.

2 T.H. Jordan, The continental tectosphere, Rev, Geophys. Space Phys. 13, 1-12, 1975.

3 T.H. Jordan, Composition and development of the continental tectosphere, Nature 274, 544-548, 1978.

4 T.H. Jordan, Continents as a chemical boundary layer, Philos. Trans. R. Soc. London, Ser. A 301, 359-373, 1981.

5 S.P. Grand and D.V. Helmberger, Upper mantle shear structure of North America, Geophys. J.R. Astron. Soc. 76, 399-438, 1984.

6 S.P. Grand and D.V. Helmberger, Upper mantle shear structure beneath the northwest Atlantic Ocean, J. Geophys. Res. 89, 11465-11475, 1984.

7 S.P. Grand, A tomographic inversion for shear velocity beneath the North American plate, EOS Trans. Am. Geophys. Union 67, 302, 1986.

8 M. Ritz and B. Robineau, Crustal and upper mantle electrical conductivity structures in west Africa: geodynamic implications, Tectonophysics 124, 115-132, 1986.

9 P.J. Wyllie, Mantle fluid compositions buffered in peridotite- $\mathrm{CO}_{2}-\mathrm{H}_{2} \mathrm{O}$ by carbonates, amphibole, and phlogopite, J. Geol. 86, 687-713, 1978.

10 P.J. Wyllie, Magmas and volatile components, Am. Mineral. 64, 469-500, 1979.

11 E. Takahashi and C. Scarfe, Melting of peridotite to 14 $\mathrm{GPa}$ and the genesis of komatiite, Nature 315, 566-568, 1985.

12 R.L. Post and D.T. Griggs, The earth's mantle: evidence of non-Newtonian flow, Science 181, 1242-1244, 1973.

13 R.L. Post, High-temperature creep of Mt. Burnet dunite, Tectonophysics 42, 74-110, 1977.

14 N.L. Carter, Steady state flow of rocks, Rev. Geophys. Space Phys. 14, 301-360, 1976. 
15 N.L. Carter and H.G. Ave Lallement, High temperature flow of dunite and peridotite, Geol. Soc. Am. Bull. 81, 2181-2202, 1970.

16 P.N. Chopra and M.S. Paterson, The experimental deformation of dunite, Tectonophysics 78, 453-473, 1981.

17 P.N. Chopra and M.S. Paterson, The role of water in the deformation of dunite, J. Geophys. Res. 89, 7861-7876, 1984.

18 S. Karato, Does partial melting reduce the creep strength of the upper mantle? Nature 319, 309-310, 1986.

19 S. Ballard III and H.N. Pollack, Diversion of heat by Archean cratons: implications for "reduced" heat-flow, EOS Trans. Am. Geophys. Union 67(16), 388, 1986.

20 A.E. Ringwood, Composition and Petrology of the Earth's Mantle, p. 150, McGraw Hill, New York, N.Y., 1975.

21 K.P. Jochum, A.W. Hoffman, E. Ito, H.M. Seufert and W.M. White, $\mathrm{K}, \mathrm{U}$ and $\mathrm{Th}$ in mid-ocean ridge basalt glasses and heat production, $\mathrm{K} / \mathrm{U}$ and $\mathrm{K} / \mathrm{Rb}$ in the mantle, Nature 306, 431-436, 1983.

22 G. Schubert and A. Reymer, Continental volume and freeboard through geological time, Nature 316, 336-339, 1985.

23 T.H. Jordan, Mineralogies, densities and seismic velocities of garnet lherzolites and their geophysical implications, in: The Mantle Sample: Inclusions in Kimberlites and Other Volcanics, F.R. Boyd and H.O.A. Meyer, eds., pp. 1-14, American Geophysical Union, Washington, D.C., 1979.

24 R.C. Liebermann, Velocity-density systematics for the olivine and spinel phases of $\mathrm{Mg}_{2} \mathrm{SiO}_{4}-\mathrm{Fe}_{2} \mathrm{SiO}_{4}, \mathrm{~J}$. Geophys. Res. 75, 4029-4034, 1970.

$25 \mathrm{~S}$. Akimoto, The system $\mathrm{MgO}-\mathrm{FeO}-\mathrm{SiO}_{2}$ at high pressures and temperatures-phase equilibria and elastic properties, in: The Upper Mantle, A.R. Ritsema, ed., Tectonophysics 131, 161-187, 1972.

26 J.M. Barton, Jr. and R.M. Key, The tectonic development of the Limpopo Mobile Belt and the evolution of the Archean cratons of southern Africa, in: Precambrian Plate Tectonics, A. Kroner, ed., pp. 185-212, Elsevier, Amsterdam, 1981

27 S.H. Richardson, J.J. Gurney, A.J. Erlank and J.W. Harris, Origin of diamonds in old enriched mantle, Nature 310 , 198-202, 1984.

28 F.R. Boyd, J.J. Gurney and S.H. Richardson, Evidence for a $150-200 \mathrm{~km}$ thick Archean lithosphere from diamond inclusion thermobarometry, Nature 315, 387-389, 1985.

29 R.O. Moore and J.J. Gurney, Pyroxene solid solution in garnets included in diamond, Nature 318, 553-555, 1985.

30 K. Bell, J. Blenkinsop, T.J.S. Cole and D.P. Menagh, Evidence from $\mathrm{Sr}$ isotopes for long-lived heterogeneities in the upper mantle, Nature 298, 251-253, 1982.

$31 \mathrm{~K}$. Bell and J. Blenkinsop, Archean depleted mantle-evidence from $\mathrm{Nd}$ and $\mathrm{Sr}$ initial isotopic ratios of carbonatites, 1986 (submitted).

32 M. Jackson and H.N. Pollack, On the sensitivity of parameterized convection to the rate of decay of internal heat sources, J. Geophys. Res. 89, 10103-10108, 1984.

33 A. Reymer and G. Schubert, Phanerozoic addition rates to the continental crust and crustal growth. Tectonics 3,63-77, 1984.

34 R.K. O'Nions, N.M. Evensen and P.J. Hamilton, Geochemical modeling of mantle differentiation and crustal growth J. Geophys. Res. 84, 6091-6101, 1979.

35 C.J. Allègre, Chemical geodynamics, Tectonophysics 81 , $109-132,1982$.

36 S.M. McLennan and S.R. Taylor, Geochemical constraints on the growth of the continental crust, J. Geol. 90, 342-361, 1982.

37 W.S. Fyfe, The evolution of the earth's crust: Modern plate tectonics to ancient hot-spot tectonics? Chem. Geol. 23, $89-114,1978$

38 R.L. Armstrong, Radiogenic isotopes: The case for crustal recycling on a near-steady-state no-continental growth earth, Philos. Trans. R. Soc. London, Ser. A301, 443-472, 1981

39 G.C. Brown, The changing pattern of batholith emplacement during earth history, in: Origin of Granite Batholiths, Geochemical Evidence, M.P. Atherton and J. Tarney, eds., pp. 106--115, Shiva, Nantwich, 1979.

40 J.F. Dewey and B.F. Windley, Growth and differentiation of the continental crust, Philos. Trans. R. Soc. London, Ser. A $301,189-206,1981$

41 J. Veizer and S.L. Jansen, Basement and sedimentary recycling and continental evolution, J. Geol. 87, 341-370, 1979.

42 P.M. Hurley and J.R. Rand, Pre-drift continental nuclei, Science 164, 1229-1242, 1969. 